Research Article

\title{
Morphological and Thermal Properties of Poly(Vinyl Alcohol)/Layered Double Hydroxide Hybrid Nanocomposite Fibers
}

\author{
A. F. Al Naim $\mathbb{D}^{1},{ }^{1}$ J. Mazher $\mathbb{D}^{1},{ }^{1}$ and S. S. Ibrahim $\mathbb{D}^{2}$ \\ ${ }^{1}$ Physics Department, King Faisal University, Al-Ahsa, Saudi Arabia \\ ${ }^{2}$ Physics Department, Faculty of Science, Cairo University, Cairo, Egypt \\ Correspondence should be addressed to A. F. Al Naim; anaim2@kfu.edu.sa
}

Received 8 August 2020; Revised 4 October 2020; Accepted 21 October 2020; Published 5 November 2020

Academic Editor: Wen Shyang Chow

Copyright (C) 2020 A. F. Al Naim et al. This is an open access article distributed under the Creative Commons Attribution License, which permits unrestricted use, distribution, and reproduction in any medium, provided the original work is properly cited.

\begin{abstract}
Nanolayered particulate of Zn-based layered double hydroxide (LDH) was prepared by a low temperature greener sol-gel method. $\mathrm{X}$-ray diffraction (XRD) studies were performed on the particles annealed at different temperatures. Hexagonal crystal structure of the as-grown LDH particulates was observed. The crystal structure was modified to tetragonal structure of layered double oxide (LDO) on annealing at $250^{\circ} \mathrm{C}$. Rietveld fittings showed a collapse of interlayer separation distance along the preferred orientation of the LDH particles as a result of heat treatment. Further, LDH particles were used as fillers of electrospun poly(vinyl alcohol) (PVA) fibers. Heat treatment of the polymer fibers was also performed at different temperatures, and thermal changes were studied by thermogravimetric analysis (TGA), Raman spectroscopy, and scanning electron microscopy (SEM) techniques. Improved interaction of fibers with LDH nanoparticles was observed and ascribed to LDH-related LDO phase transformation at higher temperature. Thermal mechanisms of the rapid weight loss in filled fibers were discussed in comparison to the pure PVA fiber losses. Experimental Raman frequencies of the composite fibers were compared with the calculated Raman modes of the enol and $\mathrm{ZnO}$ monomers. The molecular vibration frequencies were found to differ significantly due to heat treatment. Finally, the role filler in the faster and greener thermal decomposition of polymeric fibers was also discussed in the present work.
\end{abstract}

\section{Introduction}

Layered double hydroxides (LDHs) have recently been under intensive investigation, largely owing to the potential applications of LDH films in enhancing the hydrophobic nature of, for example, surfaces, biomaterial and chemical sensors, photodegradation, photocatalysis, and fuel cells [1-4]. The layered nature of $\mathrm{LDH}$ arises from the extra cationic nature of its crystalline layers, which is balanced by anionic species present in between the two positive layers [5]. The LDH structure can be compared to the hexagonal structure of anionic clays [6]. Thus, LDH materials can demonstrate a variety of physiochemical properties depending on the type of sandwiched anions [5, 7]. Poly(vinyl alcohol) (PVA) is a common, nontoxic, biofriendly polymer with enormous applications in biomedical implants arising from its chemoresistance, high water solubility, biocompatibility, and low protein absorption [8]. Poly(vinyl alcohol) is also an excellent embedding medium for a variety of fillers, such as silver nanoparticles, oxide nanoparticles, and clays, providing antibacterial, photocatalytic, and mechanical strength to the polymer composites [9]. Understandably, PVA embedding also helps in lowering the toxicity of nanomaterials and highly reactive fillers. Novel chemical and physical traits can be observed in the polymer composites of PVA with LDH fillers, and this has interesting applications in the fields of thermal management, biosensors, medical implants, gas detection, and photocatalysis [8-11]. Furthermore, the annealing of PVA-based hybrid composites is equally as helpful in the fundamental studies of the antifatigue, thermal 
TABLE 1: Details of the materials used in PVA/LDH hybrid nanocomposite fibers, with heat treatment data.

\begin{tabular}{|c|c|c|c|c|}
\hline Serial number & Sample name & Material prepared & $\begin{array}{c}\text { Growth } \\
\text { temperature }\end{array}$ & $\begin{array}{c}\text { Heat treatment } \\
\text { temperature }\end{array}$ \\
\hline 1. & LDH75 & ZnO-layered double hydroxide & $20^{\circ} \mathrm{C}$ & $75^{\circ} \mathrm{C}$ \\
\hline 2. & LDH250 or LDO & ZnO-layered double oxide & $20^{\circ} \mathrm{C}$ & $250^{\circ} \mathrm{C}$ \\
\hline 3. & PF75 & Electrospun PVA fiber & $25^{\circ} \mathrm{C}$ & $75^{\circ} \mathrm{C}$ \\
\hline 4. & PF250 & Electrospun PVA fiber & $25^{\circ} \mathrm{C}$ & $250^{\circ} \mathrm{C}$ \\
\hline 5. & CF250 & $\begin{array}{l}\text { Hybrid composite fiber of PVA-filled } \\
\text { ZnO-layered double oxides }\end{array}$ & $25^{\circ} \mathrm{C}$ & $250^{\circ} \mathrm{C}$ \\
\hline 6. & CF150 & $\begin{array}{l}\text { Hybrid composite fiber of PVA-filled } \\
\text { ZnO-layered double oxides }\end{array}$ & $25^{\circ} \mathrm{C}$ & $150^{\circ} \mathrm{C}$ \\
\hline 7. & CF75 & $\begin{array}{l}\text { Hybrid composite fiber of PVA-filled } \\
\text { ZnO-layered double oxides }\end{array}$ & $25^{\circ} \mathrm{C}$ & $75^{\circ} \mathrm{C}$ \\
\hline
\end{tabular}

stability, and antifracture traits of polymers as in extensive applications in soft robotics and hydrogel-based soft machines [12].

The sol-gel method of synthesis that involves moderate temperatures of synthesis with respect to the solid-state growth routes and lack of harmful toxic solvents during the synthesis process is generally known as the green sol-gel method [13]. We were interested in deploying this green sol-gel synthesis by adopting a room-temperature growth process and employing only common, nontoxic solvents in our environmentally friendly process of preparation of $\mathrm{ZnO}-\mathrm{LDH}$ powders. The novel green methods of synthesis are highly important, as exposure to harmful solvents can be dangerous and create long-term human health issues, such as respiratory and thyroid syndromes, as well as polluting the soil and atmosphere [14].

Layered double oxide (LDO) can be formed by calcining the parent LDH compound [15]. A variety of interesting traits are exhibited by the LDO material, such as an increase in the surface area [16], binder-induced tuning of the angle between super hydrophilic and hydrophobic contacts [16], and higher photocatalysis for faster photodegradation of dyes [17]. Moreover, battery electrodes prepared from Zn-LDO have been reported to show larger discharge capacity, reversibility, and layer cycle lifetime [18]. In addition, Zn-LDOincorporated LDH materials have recently been deployed to sense acetone, which is an important diabetic biomarker in human plasma [19]. However, in the contemporary literature, the calcination of $\mathrm{Zn}$-based LDH compounds has only been reported to convert into hexagonal $\mathrm{Zn}$-LDO layers, albeit at high calcination temperatures of $\sim 600^{\circ} \mathrm{C}[15,17]$. Furthermore, quite often in the literature, nongreen synthesis routes have been selected to prepare the $\mathrm{ZnO}$-based $\mathrm{LDH}$ compounds using higher synthesis-chamber temperatures, higher chamber pressures, and higher annealing-furnace temperatures [18]. To the best of our knowledge, a green sol-gel route for $\mathrm{Zn}$-based $\mathrm{LDH}$ preparation and their PVA composites have not been reported before in the available literature. Electrospun fibers of a blend of LDH nanofiller with polymers are of considerable scientific interest owing to myriad of applications in bioengineering, drug molecule delivery, diagnosis, and biomimetics, thermal management, energy, and catalysis $[20,21]$. The successful and homogeneous for- mation of the composite material largely depends upon the extent to which the PVA chains are intercalated in the double-layered material [10]. Clay-polymer composites are already popular, due to successful composite formation, and are deployed in large-scale industrial applications ranging from synthetic fabrics to automobiles, replacing conventional plastics [11]. One of the potential applications of the nanofiller blending in polymers arises in the realization of greener electronics in which low temperatures are required for thermal decomposition of the electronic components $[22,23]$. In this report, we present our results for the synthesis of Zn-based LDH clay and the effects of annealing on the structural properties of LDH. Thermogravimetric analysis (TGA) and Raman analysis of the composite PVA fibers containing LDH fillers were performed with respect to annealing temperatures.

\section{Materials and Methods}

2.1. Synthesis of Zn-LDH and Nanocomposite Fibers. Zinc acetate, of $99.98 \%$ purity and purchased from Sigma-Aldrich, USA, was dissolved in ethanol and acetylacetone in a $0.05: 1: 0.005$ molar ratio and stirred for $1 \mathrm{~h}$ at $40^{\circ} \mathrm{C}$. A solution of $1 \mathrm{M}$ ethanol- $\mathrm{NaOH}$, of $99.7 \%$ purity and purchased from Sigma-Aldrich, USA, was added to the solution until a constant $\mathrm{pH}$ value of $\sim 8$ was obtained. A thick $\mathrm{LDH}$ gel was formed, which, on drying at $75^{\circ} \mathrm{C}$ for 2 days, converted into a white clay-type solid. This $\mathrm{LDH}$ clay was powdered using a pestle and mortar and mixed with PVA, of $99.9 \%$ purity and purchased from Sigma-Aldrich, USA, in a weight ratio of $1 \mathrm{~g}$ in the $25 \mathrm{ml}$ in water. The PVA/LDH melt was drawn and solidified into fibers using a Nanofiber Electrospinning Unit (Kato Tech, Japan). Electrospinning was performed at a fixed needle-cylinder distance of $\sim 9.5 \mathrm{~cm}$, a rotational speed of $\sim 3.6 \mathrm{rpm}$, and a voltage of $\sim 23 \mathrm{kV}$. Fibers were dried at $75^{\circ} \mathrm{C}$ for 2 days. Overall, seven samples of $\mathrm{LDH}$ and hybrid nanocomposite fibers were prepared, and their treatment details are shown in Table 1.

2.2. Materials Characterization and Simulation. A field emission scanning electron microscope (JSM-7500; Jeol) was used for imaging the samples in high-resolution mode with 100,000x magnification, and a powder X-ray diffractometer 


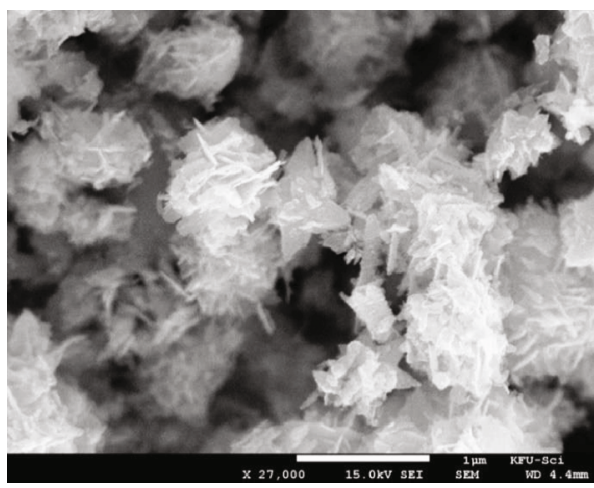

(a)

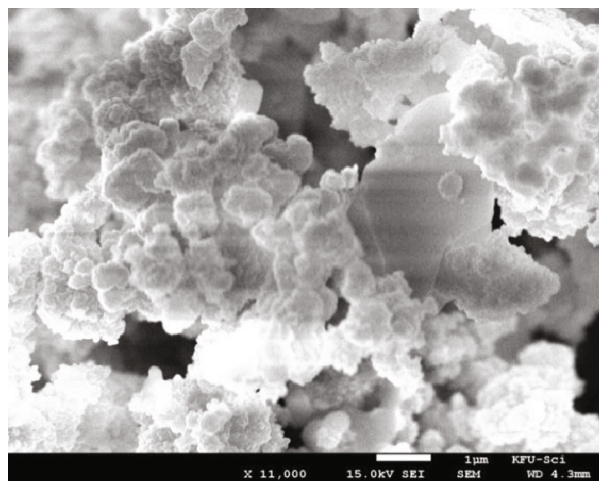

(c)

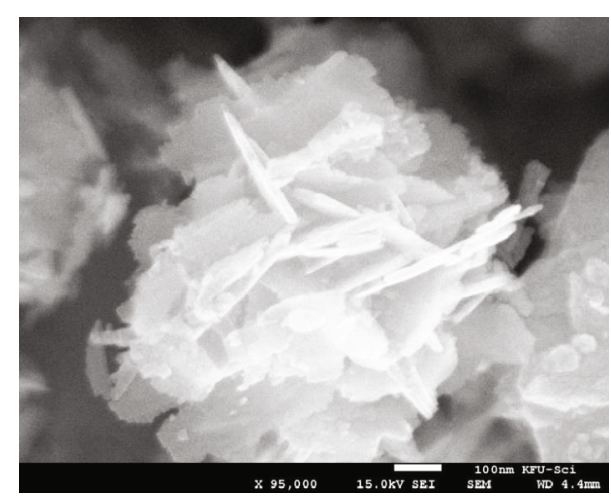

(b)

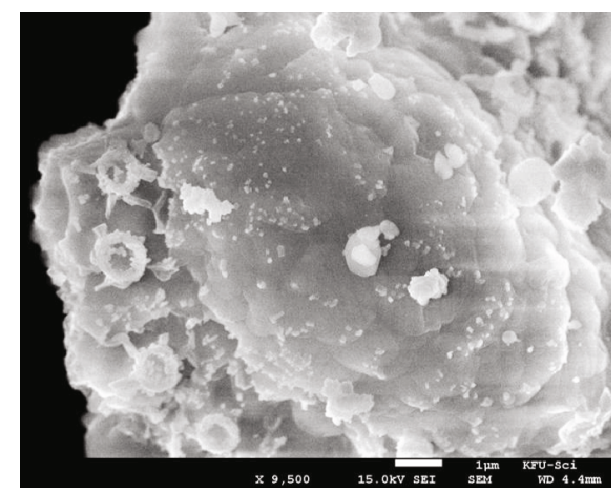

(d)

Figure 1: (a) Scanning electron microscopy images of as-prepared Zn-layered double hydroxide (LDH) clay powder (LDH75). (b) Highresolution electron microscopic image of the LDH75 sample. (c) The effects of heating $\left(250^{\circ} \mathrm{C}\right)$ on the LDH sample, which compacted into clusters of layered double oxide (LDO) layers. (d) Electron microscopic image of a sizeable layered region of the LDO sample.

(Ultima IV; Rigaku, Japan) was used for X-ray diffraction (XRD) analysis of the LDH powders. Phase analysis and (hkl) plane indexing of the $\mathrm{LDH}$ powders were performed using the FullProf Rietveld analysis software [20]. An X-ray photoelectron spectrometer (ESCA-II; Omicron) was utilized to perform chemical shift analysis of the LDH powders. Carbon 1 s (sp3) edge was used to calibrate edge energy at $0.05 \mathrm{eV}$ resolution. A TA Instruments-Q500 analyzer was employed for the TGA of LDH-PVA fibers at a $10^{\circ} \mathrm{C} / \mathrm{min}$ ramp in an $\mathrm{N}_{2}$ environment. Raman spectra of fibers were collected using a confocal microscopic spectrometer (LabRAM-HR; Horiba) with a laser excitation line of wavelength $632.8 \mathrm{~nm}$. A 50x objective was used with an $\sim 50 \%$ numerical density filter on samples, and Raman signals were scanned using a 1800-line/mm grating for the Si detector. The molecular vibrations of the hexagonal-phase $\mathrm{ZnO}$ and the enol monomer of PVA were calculated by the reduced Hartree-Fock (RHF) method implemented in the ORCA software version 4.0 [24].

\section{Results and Discussion}

3.1. Morphological and Structural Studies of $\mathrm{Zn}-\mathrm{LDH}$ Nanoparticles. The LDH powder samples were morphologically, structurally, and compositionally characterized using scanning electron microscopy, XRD, and X-ray photoelectron spectrometry (XPS) techniques, respectively.
Figure 1(a) shows an electron microscope image of dried powder from the LDH75 sample. The layered nature of this pure LDH sample is apparent from the visible platelets. The high-resolution image $(\times 100 \mathrm{k}$ magnification $)$ of the pure LDH in Figure 1(b) clearly manifests strata-type structures comprising of vertically upright plates. Similarly, the platelets and the layered nature of the oxide are observed in the LDO sample in Figure 1(c). However, the LDO morphology is more compacted, resulting from changes in the interlayer separation and subsequent crumpling of the layers upon heating. In some regions, very large layers of the LDO structures with dimensions of $\sim 1-5 \mu \mathrm{m}$ are also visible, as shown in Figure 1(d). The presence of such large layer structures indicates that the very fine LDO platelets have lumped together into larger agglomerations of clusters during heat treatment of LDH, showing the higher inter- and intralayer interactions among the double layers.

The experimental XRD spectrum of the pure $\mathrm{Zn}-\mathrm{LDH}$ sample (LDH75) is shown in Figure 2(a), along with the structural refinement data. Rietveld fitting [25] of the XRD profile shows the hexagonal (P6) symmetry of the pure $\mathrm{LDH}$ powders, as also described by the red curve fit in Figure 2(b). The Miller planes of the major reflection peaks were (003), (118), (220), (416), (0019), and (603), confirming the hexagonal structure of the LDH layers. The cell constants determined from the structural analysis were as follows: $\mathrm{a}(8.2934), \mathrm{b}(8.2934), \mathrm{c}(23.5089), \alpha\left(90^{\circ}\right), \beta\left(90^{\circ}\right)$, and $\gamma\left(120^{\circ}\right)$. 


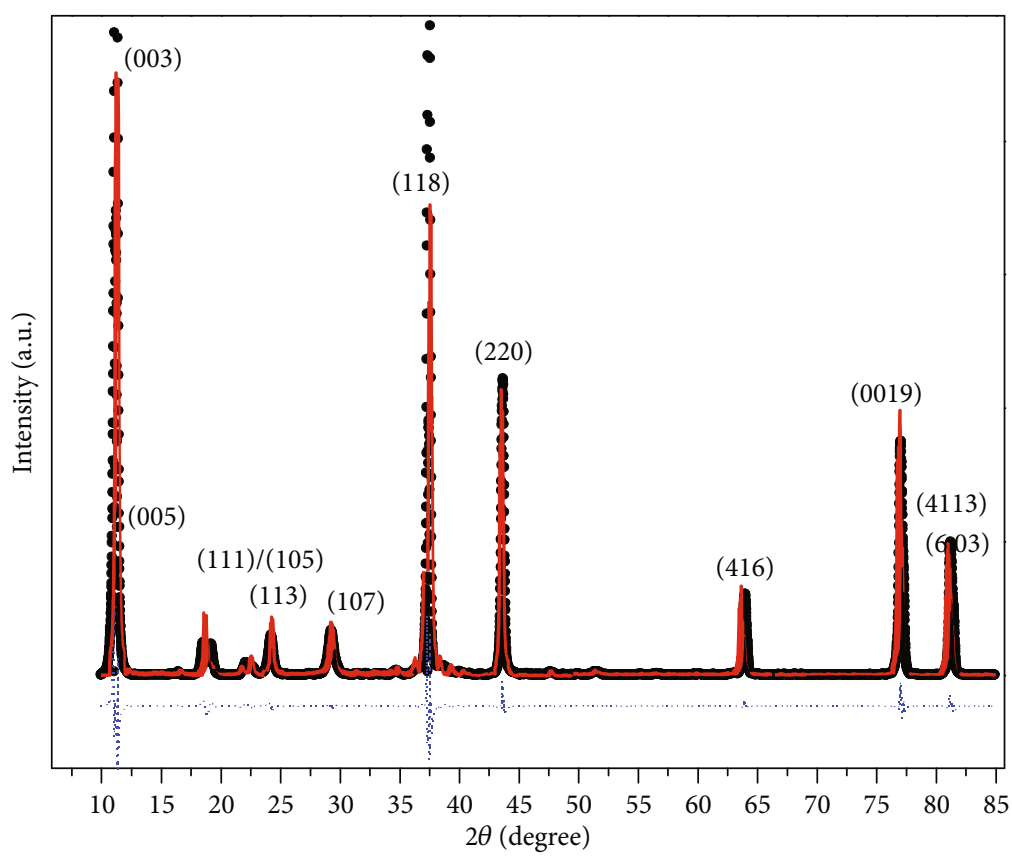

- Experimental XRD profile

- Hexagonal symmetry

……... Difference

(a)

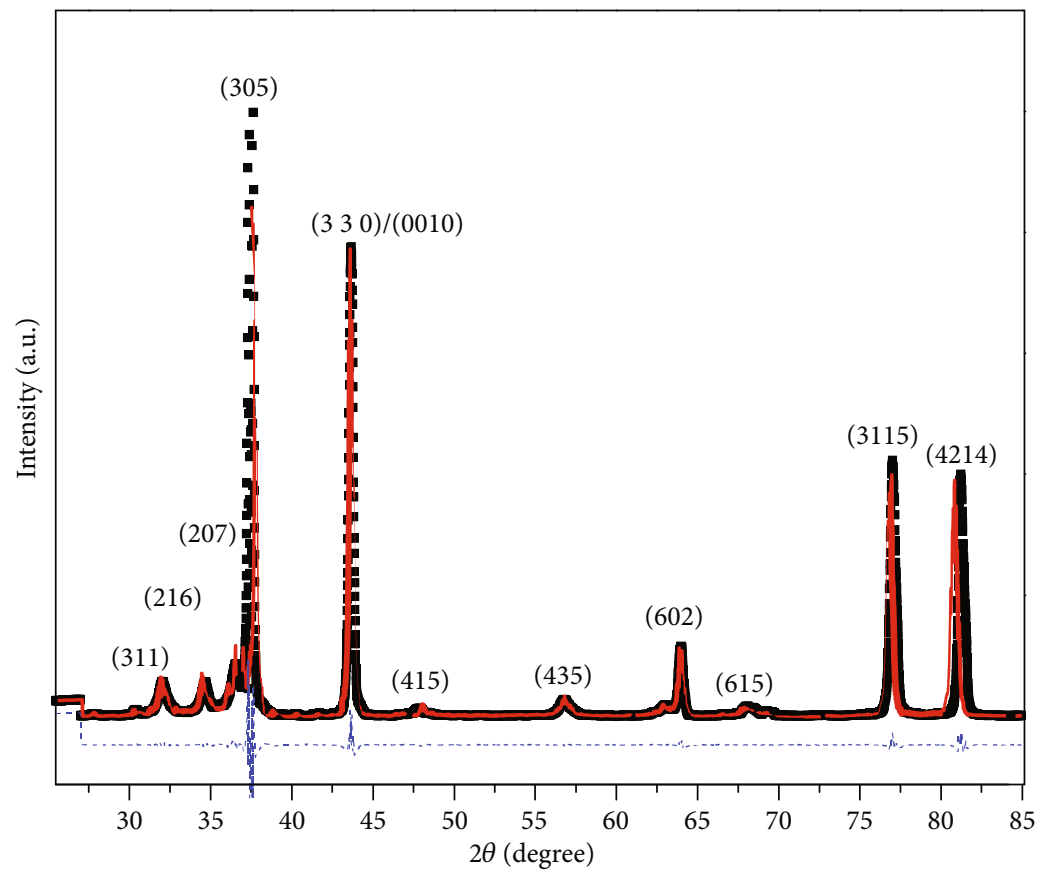

- Experimental XRD profile

— Tetragonal symmetry

……... Difference

(b)

Figure 2: (a) X-ray diffraction plot of as-prepared layered double hydroxide (LDH) powder (sample LDH75) and structural refinement using Rietveld fitting ( $\mathrm{P} 6 / \mathrm{m} \mathrm{m} \mathrm{m}$ ) on the X-ray diffraction (XRD) profile, along with the difference fitting curve. (b) Tetragonal (P4) structural fitting of the X-ray diffraction plot of the layered double oxide (LDO) sample. 
The hexagonal (brucite) structure of Zn-based LDH clays has also been reported in the literature [26]. Owing to the strongest peak intensity of (003) XRD reflection positioned at the smallest $2 \theta$ value of $\sim 11.5^{\circ}$, we expect that the preferred orientation of the as-formed LDH powder was along the (003) plane's direction. Clearly, the interplanar separation distance along the (003) plane was large enough $(d$ value $\approx 1.1 \mathrm{~nm}$ ) to allow the process of molecular intercalation. Notably, the annealed LDH sample or the LDO sample, showed a lack of certain X-ray reflections, and the most intense reflection, indexed as (003), disappeared on annealing. The change in reflections indicates a possible phase transformation, which was subsequently confirmed by the Rietveld profile fitting. The LDO's XRD spectrum, as shown in Figure 2(b), also fitted well with the tetragonal symmetry (P4) pattern. The (hkl) planes of the major X-ray peaks obtained from the structural analysis for LDO250 were (305), (330), (0010), (602), (3115), and (4214). The cell constants determined from the structural analysis were $\mathrm{a}(8.8089), \mathrm{b}(8.8089)$, $c(20.7169), \alpha\left(90^{\circ}\right), \beta\left(90^{\circ}\right)$, and $\gamma\left(90^{\circ}\right)$. However, the LDO layers were also clearly characterized by large interlayer separation along the c-vector. Therefore, the LDO layers were equally suitable for the exfoliation and intercalation of polymer chains.

Only two binding energy peaks related to $\mathrm{O}$ and $\mathrm{Zn}$ atoms were observed in the XPS data analysis. Highresolution XPS spectra corresponding to LDH75 and LDO samples are shown in Figure 3 for O1s and $\mathrm{Zn} 2 \mathrm{p}$ electronic binding energies. Figures $3(\mathrm{a})$ and $3(\mathrm{~b})$ represent $\mathrm{O} 1 \mathrm{~s}$, and Figures 3(c) and 3(d) represent zinc (2p) binding energies before and after the annealing of $\mathrm{LDH}$ samples, respectively. The O1s peak had binding energy contributions from oxygen atoms present in the lattice layers (native-O) as well as from uncoordinated hydroxide $(\mathrm{OH})$ groups present in out-oflattice configurations. The native-O1s peak had lower binding energy because oxygen accepted electrons from electropositive $\mathrm{Zn}$ during metal-oxide formation. In contrast, the hydroxide peak was shifted towards a comparatively higher binding energy $(\sim 1.8 \pm 0.4 \mathrm{eV})$ owing to electron sharing with the $\mathrm{H}$ atom of the $\mathrm{OH}$ group. The shift between the two different $\mathrm{O}$ atoms was small and usually smeared, even in the high-resolution spectrum, due to instrumental broadening. However, deconvulation of the O1s peak for sample $\mathrm{LDH} 75$ revealed the positions of the two peaks at $530.3 \mathrm{eV}$ and $532.1 \mathrm{eV}$. Similarly, for sample LDO, the native-O and hydroxide peaks were positioned at $530.3 \mathrm{eV}$ and $532.3 \mathrm{eV}$. The percentage of $\mathrm{O}$ atoms in native- $\mathrm{O}$ and uncoordinated hydroxide positions can be calculated by taking area ratios of the two peaks. For the LDH75 sample, the percentage of $\mathrm{O}$ atom occupancy in native-O positions was $67 \%$, while for hydroxide positions, the occupancy was only $33 \%$. Thus, the majority of $\mathrm{O}$ atoms were coordinated in the anionic lattice layers of the $\mathrm{LDH}$. The native- $\mathrm{O}$ occupancy of $\mathrm{O}$ atoms increased to $74.5 \%$ in the annealed sample, LDO250; however, the hydroxide occupancy decreased to $25 \%$ in the sample, owing to some dehydration taking place during annealing. The $2 \mathrm{p}$ XPS spectrum of $\mathrm{Zn}$ atoms showed a very large spin-orbit splitting gap $(\sim 23 \mathrm{eV})$, and high-resolution binding energies were recorded only for $2 \mathrm{p}_{3 / 2}$ electronic spins, as shown in Figures 3(c) and 3(d). We observed no change in the binding energy nor in the shape of $\mathrm{Zn} 2 \mathrm{p}_{3 / 2}$ peaks, found to be centered at $1022 \mathrm{eV}$, with respect to annealing temperature. Therefore, all the $\mathrm{Zn}$ atoms were fully coordinated in the cationic lattice of the layers of LDH material.

The XPS measurements also provided useful information about the Zn-rich or O-rich stoichiometry of the LDH samples. Using the atomic sensitivity factors adopted by $\mathrm{Xu}$ et al. [27] (4.8 for $\mathrm{Zn}$ and 0.66 for O), we can find the atomic percentage ratio of $\mathrm{Zn}$ and $\mathrm{O}$ atoms in an $\mathrm{LDH}$ sample. The XPS results showed that the atomic ratio $\mathrm{O} / \mathrm{Zn}$ was 3.15 . The $\mathrm{LDH}$ samples prepared in the current work were $\mathrm{O}$ rich and $\mathrm{Zn}$ deficient. The $\mathrm{Zn}$ deficiency in the $\mathrm{LDH}$ is expected, due to the presence of anionic $\mathrm{O}$ in between the double layers of $\mathrm{LDH}$ and $\mathrm{LDO}$ materials. Moreover, the $\mathrm{Zn} / \mathrm{O}$ ratio remained almost similar in both the LDH75 sample and the air-annealed LDO sample ( 3.42), indicating the stability of the anionic species with respect to the thermal degradation. An excess of $\mathrm{O}$ atoms is also naturally expected in the typical layered double compounds, owing to the large interlayer separation and presence of anionic species, such as $\mathrm{OH}^{-}$and $\mathrm{CO}_{3}{ }^{-}$, as well as $\mathrm{H}_{2} \mathrm{O}$ in between layers.

3.2. Morphological and Thermal Studies of PVA/LDH Fibers. Scanning electron microscopy images of the pure-fiber sample (PF75) and annealed composite fibers (CF250) are shown in Figure 4. As-prepared and $75^{\circ} \mathrm{C}$-dried fibers, both with and without LDH fillers, displayed straight and rigid morphology with a uniform diameter of roughly $\sim 100 \mathrm{~nm}$ as can be seen from Figure 4(a). Further, the diameters of the fibers remain fairly constant across their length confirming the diametric uniformity of the fibers. Using the high-resolution image, Figure 4(d) of PVA/LDH fibers, the average number of particles $/ \mu \mathrm{m}^{2}$ is counted and the typical surface particle density of the nanofillers in fibers is $\sim 1.4 / \mu \mathrm{m}^{2}$. Thus, the electrospinning process of the blended fibers yields both diametrically uniform fibers and a high particle density in the fibers. Moreover, Figure $1(d)$ is also used to calculate the average particle size of the filler distribution in the PVA/LDH composite fiber, as shown in Figure 4(e). It is found that the dispersion of the LDH nanofillers has an average particle size of $45 \pm 15$ $\mathrm{nm}$ indicating the presence of nearly monodispersive nanostructures in the blended fibers. In the scanning electron microscope image, dehydrated LDH-filled fibers, annealed at $250^{\circ} \mathrm{C}$, can be seen acquiring intertwined structures. It is possible that during annealing, thermal stress and PVA decomposition were responsible for the degradation of the fiber mesh network. However, both the fibrous nature and diameter uniformity remained preserved even after annealing.

The TGA curve of pure PVA fibers (PF75) shows two characteristic weight loss regimes of PVA related to its dehydroxylation and subsequent organic material blazing (Figure 5). The initial loss starting from $200^{\circ} \mathrm{C}$ corresponds mainly to a decrease in the alcohol content of the fibers and the loss of the hydroxyl $(\mathrm{OH})$ groups, whilst the second mass loss starting from $300^{\circ} \mathrm{C}$ corresponds mainly to the complete carbonization of the PVA. For the sample PF75, the 


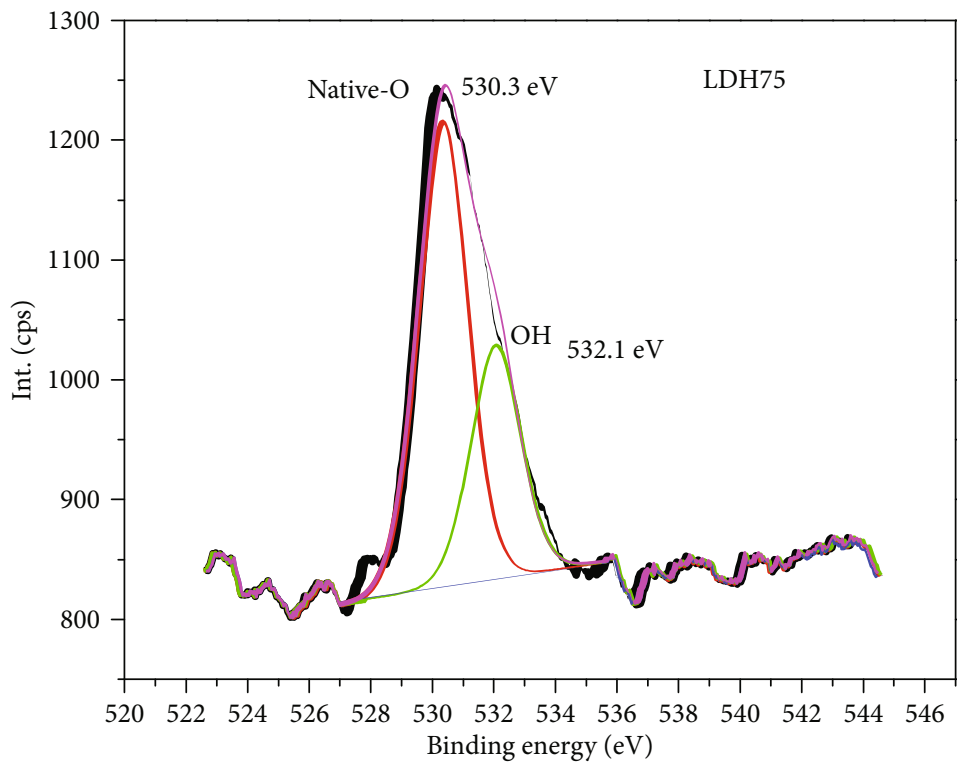

(a)

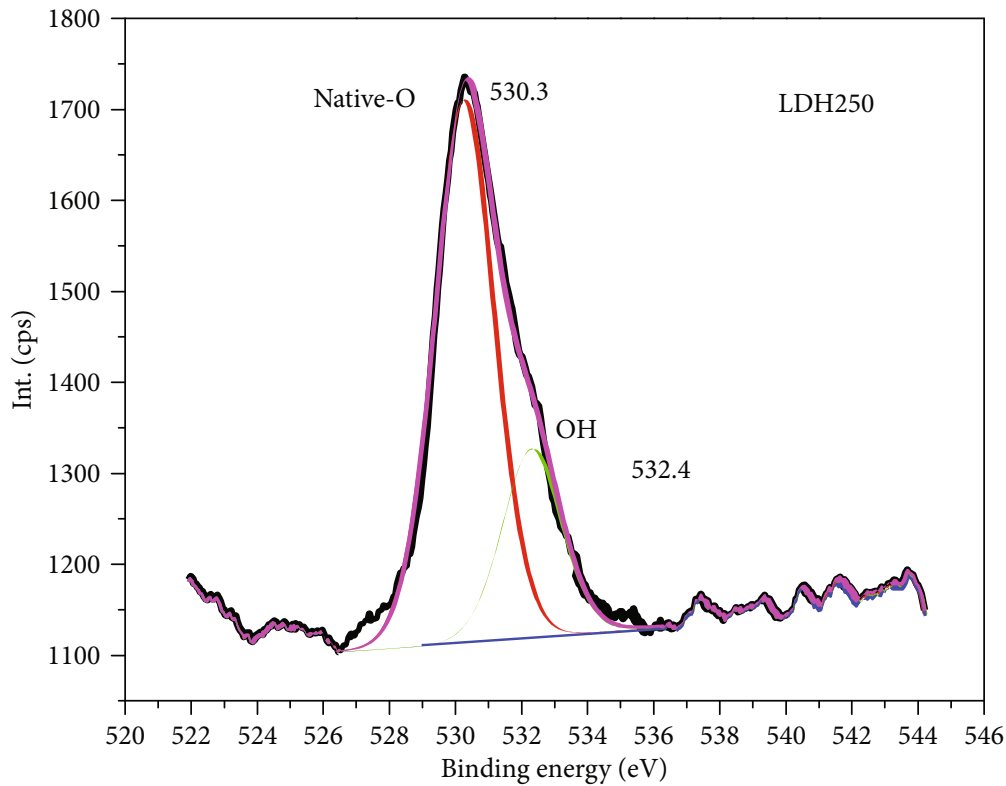

(b)

Figure 3: Continued. 


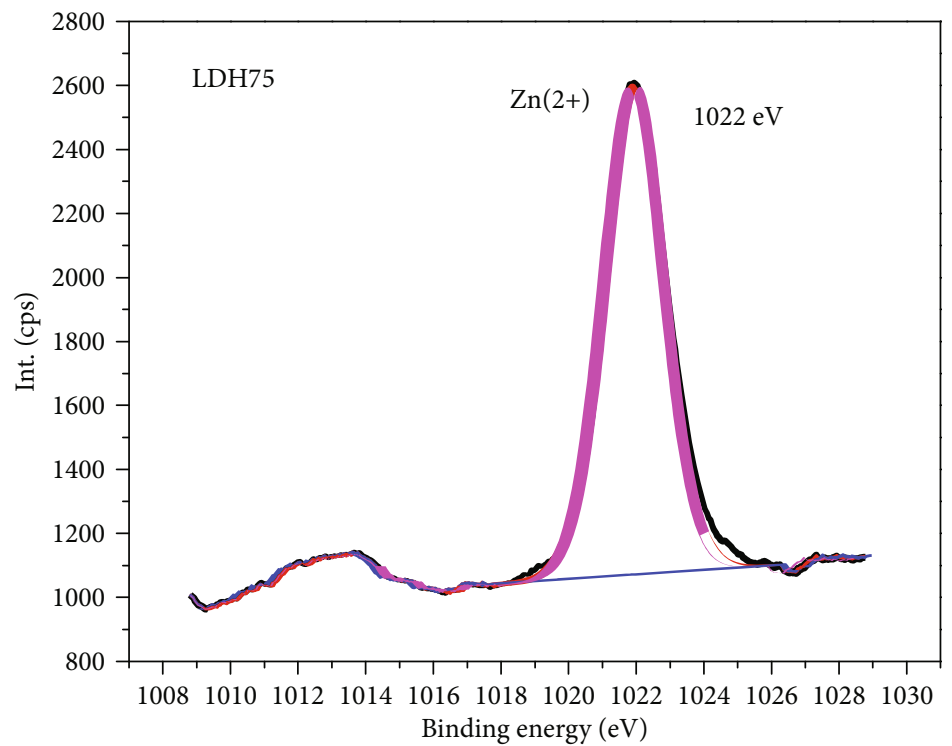

(c)

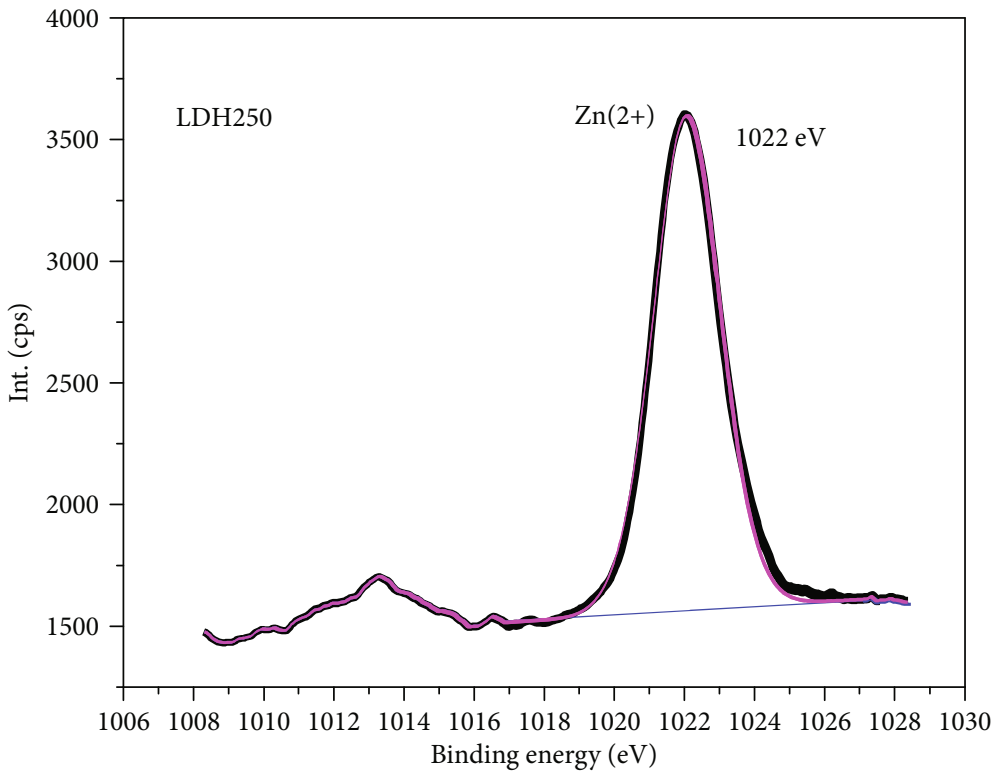

(d)

Figure 3: High-resolution X-ray photoelectron spectra of samples LDH75 and LDO (LDH250) at (a, b) oxygen (1s) and (c, d) zinc (2p) binding energies. The top and bottom rows represent before and after annealing, respectively.

temperatures of the dehydroxylation and blazing peak positions are correspondingly marked by second-derivative peaks at $320^{\circ} \mathrm{C}$ and $440^{\circ} \mathrm{C}$, as shown in Figure $5(\mathrm{a})$. We have found that the dehydroxylation peak position reduced to $300^{\circ} \mathrm{C}$ in the LDH-filled fibers (CF75), as shown in Figure 5(b). Similarly, a simultaneous early blazing temperature was also observed in the LDH-filled fibers, and this was reduced by $\sim 20^{\circ} \mathrm{C}$. Therefore, rapid and early TGA losses were observed in the LDO-filled fibers. The concurrent reduction of both of the loss peaks also indicates a type of localized sample heating in the filled PVA fibers.

The rapid loss in the filled fibers' weight is depicted by the schematic model in Figure 6, which indicates a possible mechanism of sample heating. Using the model, one can explain the causes of the uniform lowering of the two TGA signature peaks. The schematic is divided into five steps: (i) intercalation of PVA chains in the LDH layers; (ii) melt formation of PVA and ZnO-LDF hybrid composite; (iii) drawing and solidification of the polymer melt into fibers; (iv) heat treatment of fibers and LDH-to-LDO transformation at $250^{\circ} \mathrm{C}$; and $(\mathrm{v})$ further heating of samples, exhibiting rapid weight loss. During steps (i)-(iii), the model first predicts the intercalation of PVA chains in the layers of LDHs, leading to the formation of rapid heating zones. On further increase in temperature, the $\mathrm{LDH}$ clusters present in CF75 fibers are expected to transform into LDO clusters at $\sim 250^{\circ} \mathrm{C}$. During the sample heating, the LDO oxide clusters can act as hot centers, owing to their higher thermal conductivity in 


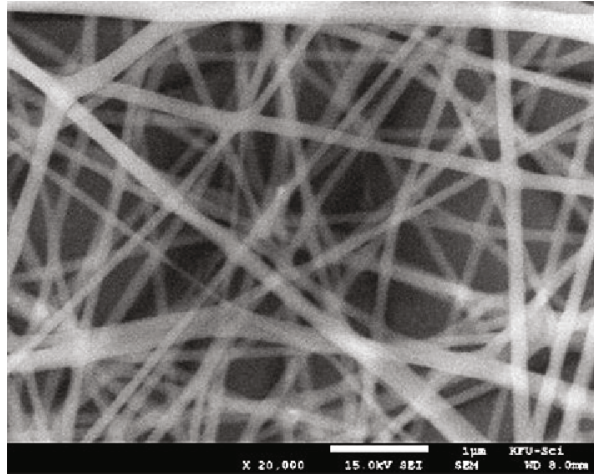

(a)

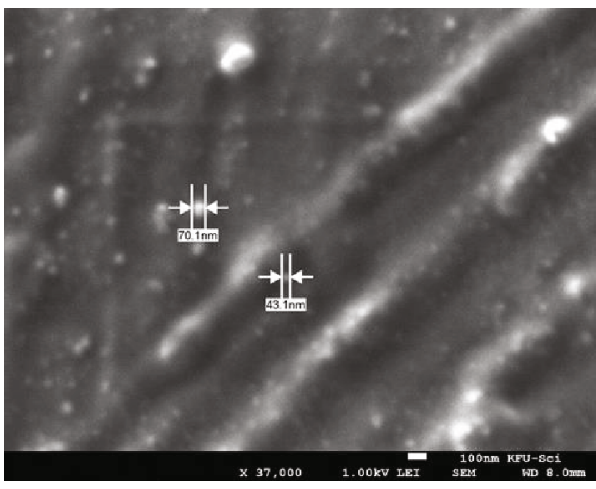

(c)

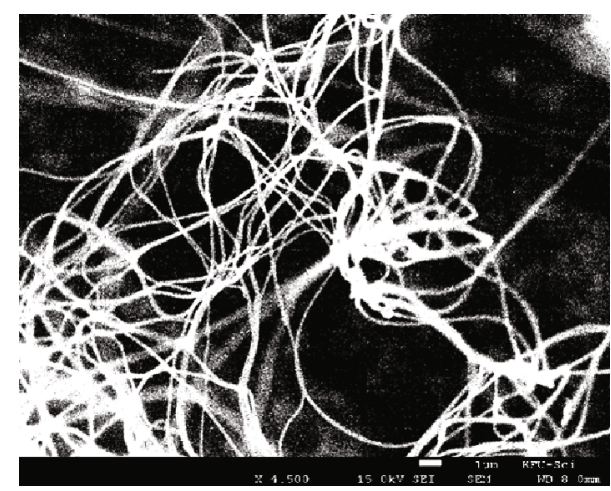

(b)

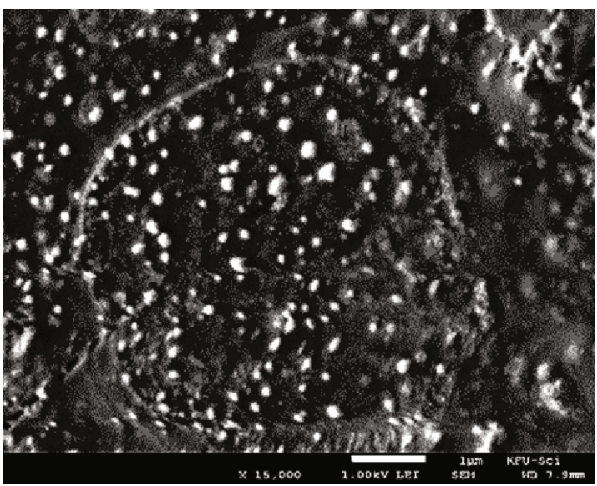

(d)

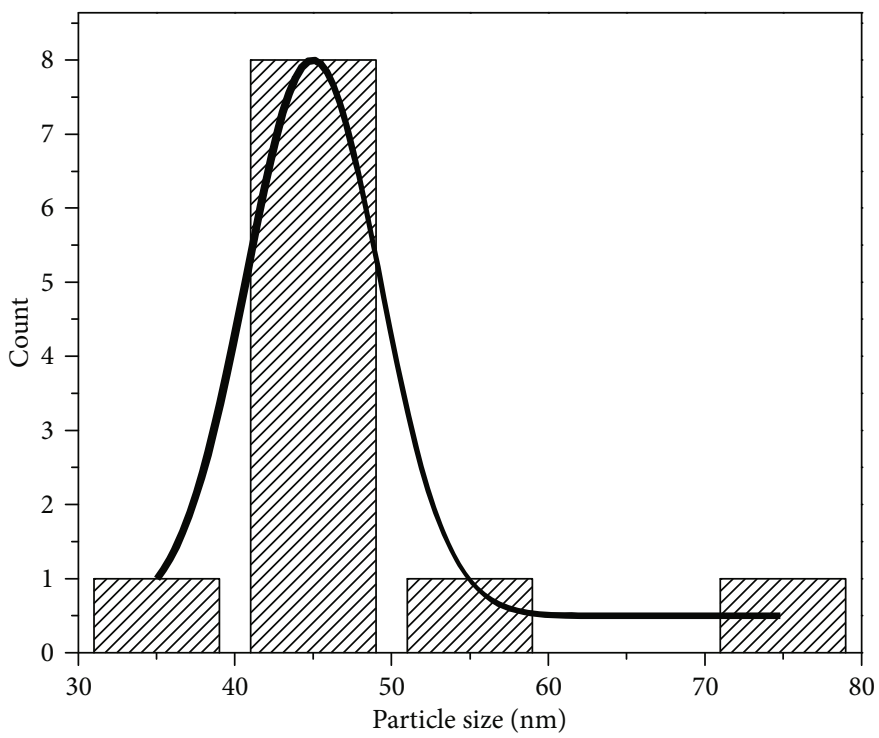

(e)

Figure 4: (a) Scanning electron microscopy image of electrospun fibers of PVA and LDH fillers dried at $75^{\circ} \mathrm{C}$ (PF75). (b) Scanning electron microscopy image of annealed fibers of PVA and LDH fillers (CF250). (c) High-resolution image showing individual ZnO nanoparticle fillers inside the fibers. (d) High-resolution image of the dispersion of nanoparticles inside the PVA matrix. (e) Dispersion of the nanoparticles is centered at $45 \mathrm{~nm}$, and the size distribution fits a Gaussian curve with a full width at half maximum of $\sim 15 \mathrm{~nm}$.

comparison with that of the alcohols. The process of LDO formation in the fibers is accomplished in step (iv), and, on further increasing the temperature to $>250^{\circ} \mathrm{C}$, a thermal gradient between PVA and LDO guides hot centers to move towards the fiber surface. Once the migration of hot centers towards the surface of fibers has occurred, as shown in step (v), the fiber surface becomes more volatile, further contributing to rapid dehydroxylation and loss of organic fibrous content. Thus, the model adequately explains the rapid thermal losses in the PVA/LDO fibers. Alternatively, in the 


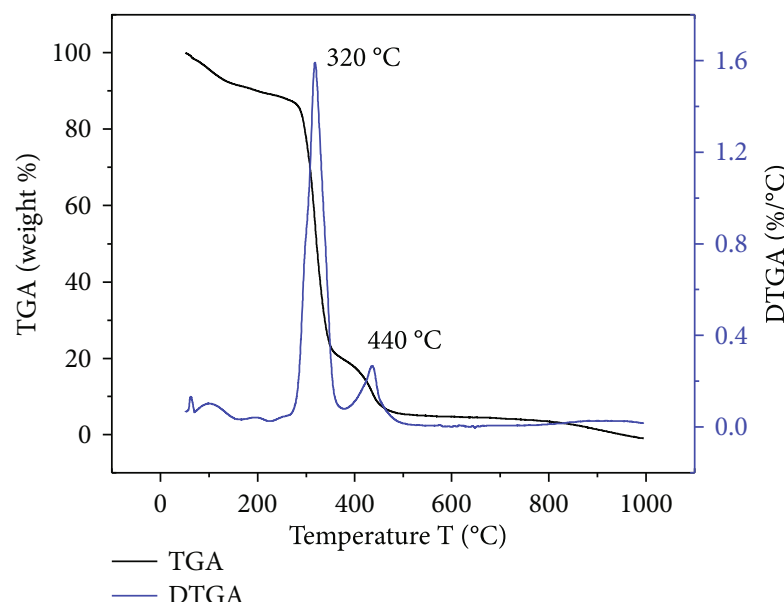

(a)

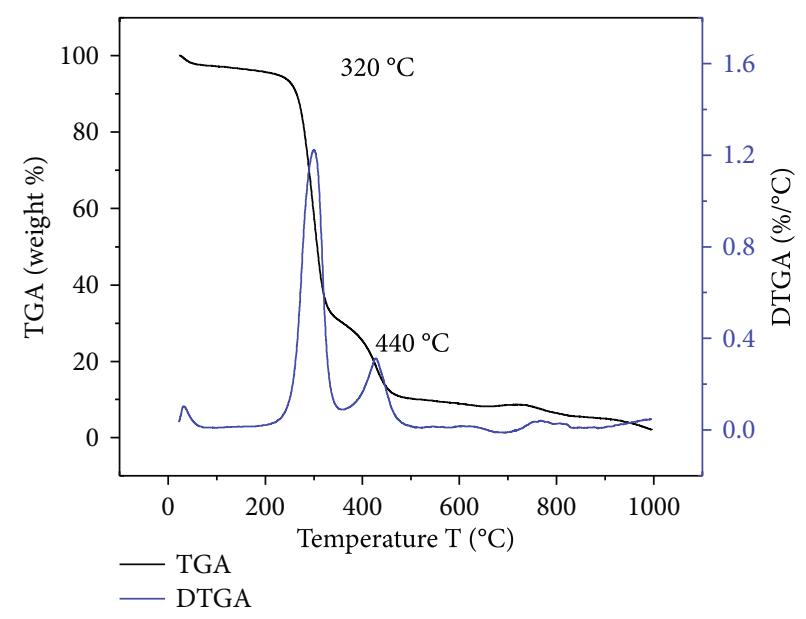

(b)

FIGURE 5: (a) Thermogravimetric (TGA) and differential-thermogravimetric (DTGA) curves for pure poly(vinyl alcohol) (PVA) fibers (PF75) are shown in black and blue, respectively. (b) TGA results for composite fibers (CF75) comprising of the layered double hydroxide-filled PVA fibers.

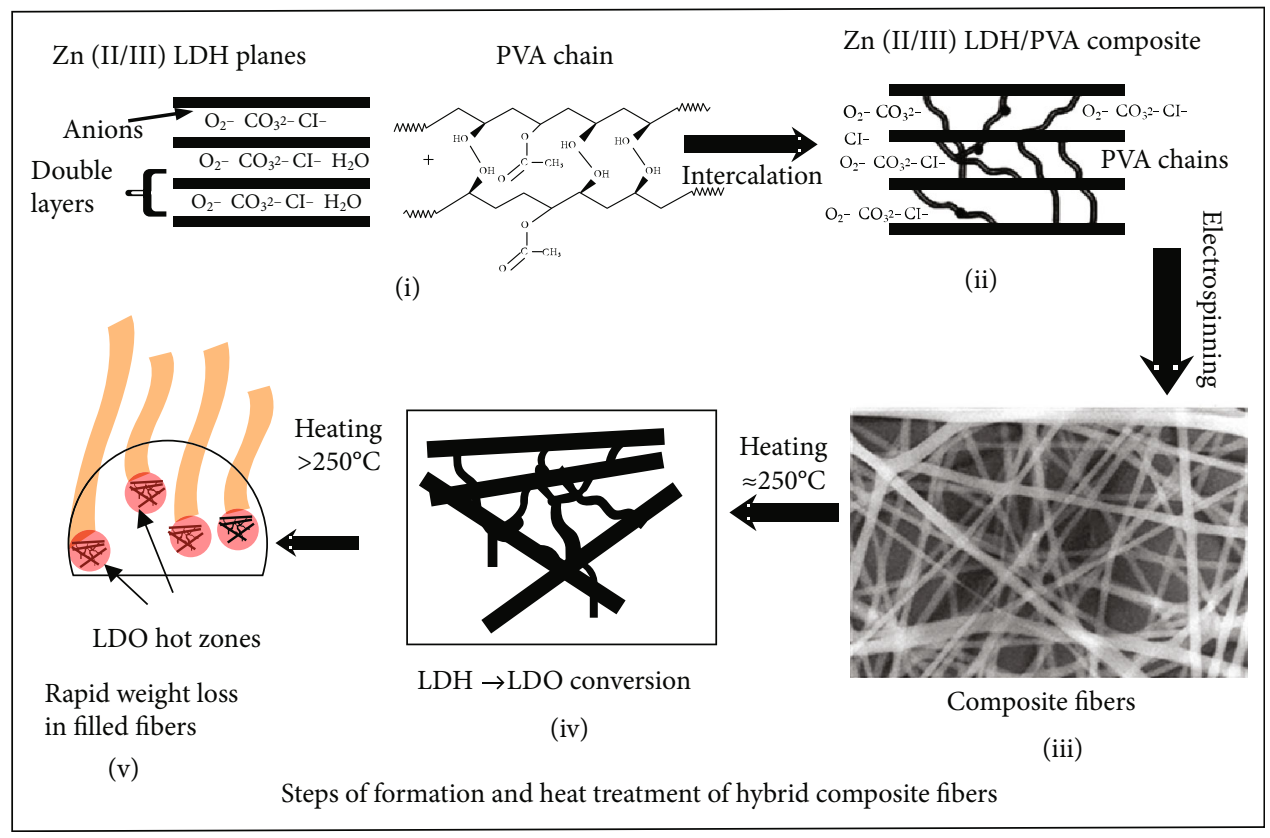

Figure 6: A schematic depicting the rapid thermogravimetric loss in the layered double hydroxide- (LDH-) filled fibers with respect to pure poly(vinyl alcohol) (PVA) fibers. The model predicts nonuniform sample heating by the formation of hot center layered double oxide (LDO) particles and their subsequent migration.

literature, a decrease in the intrinsic viscosities of the polymers has been ascribed to the thermal instability and degradation of polyethylene fibers [28]. Certainly, the lower loading fraction of oxide particles in the fiber, the higher surface area of fibers, and filler-matrix interactions are some important parameters to fundamentally explore observed thermal instability and rapid weight loss in hybrid composite fibers. Thus, a rapid thermal degradation at low temperatures is observed as a result of the $\mathrm{LDH}$ nanofiller blending, and that may be useful in the greener thermal decomposition of polymer products.
3.3. Vibrational Studies of PVA/LDH Fibers. The molecular vibration frequencies of four-atom cells of hexagonal zinc oxide and the enol monomer were calculated after the optimization of their full geometric structure. The calculated frequencies and force vector plots of the corresponding vibrations are presented in Table 2 .

$\mathrm{Zn}-\mathrm{O}$ vibrations comprised mainly of wagging, symmetrical, and asymmetrical stretching modes at comparatively lower frequencies $\left(<800 \mathrm{~cm}^{-1}\right)$, whilst the enol monomer vibrations were found to mainly show twisting, rocking, 


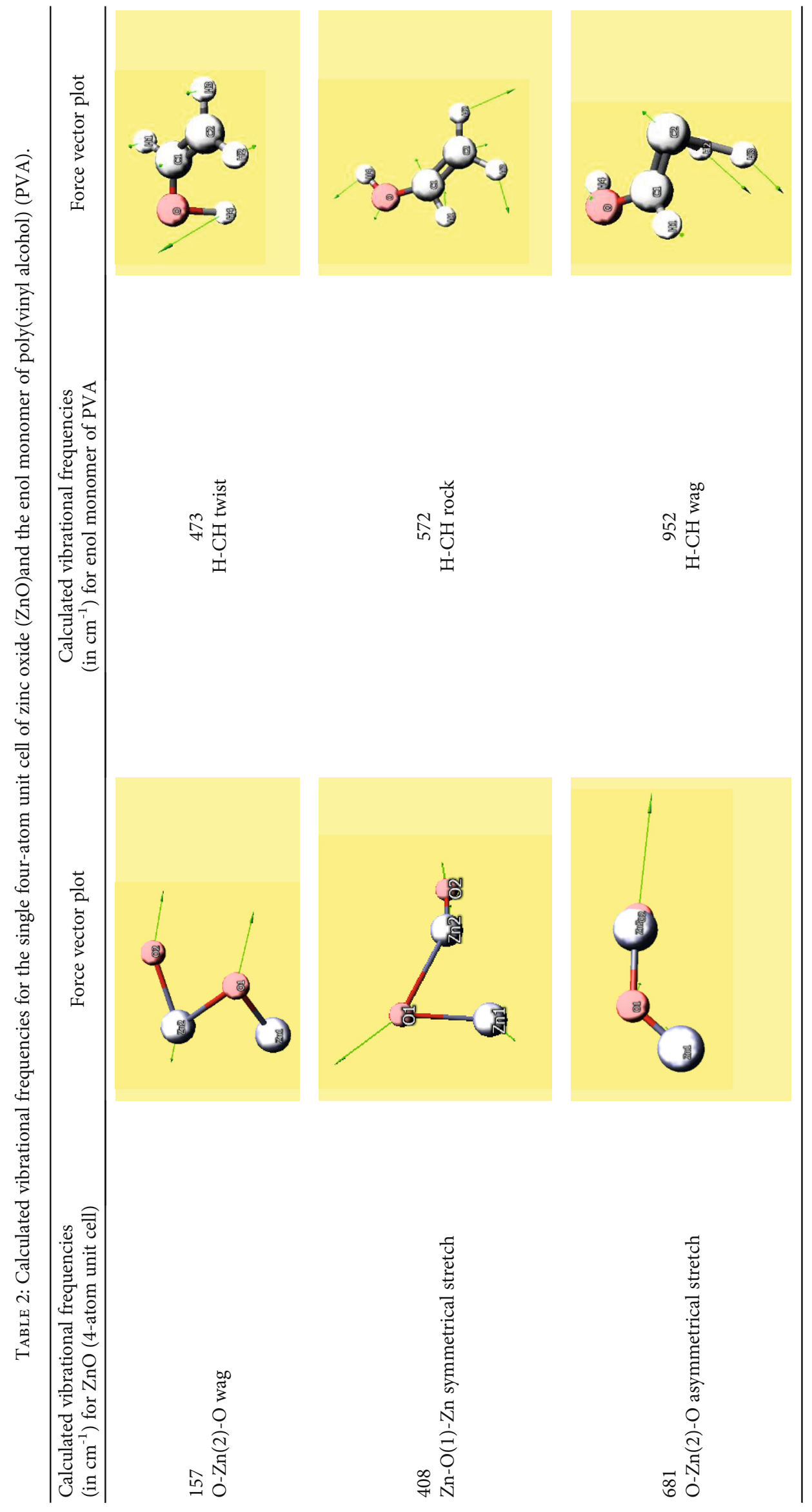




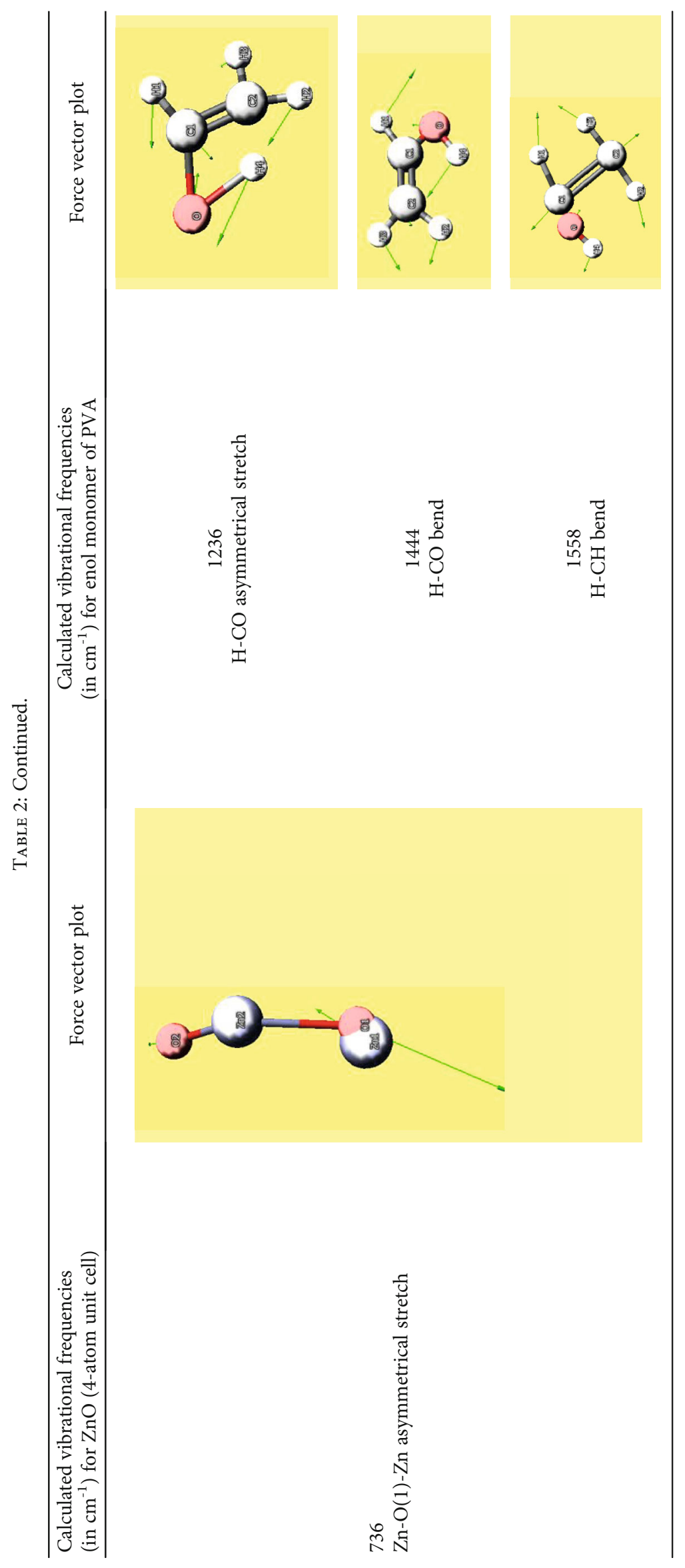




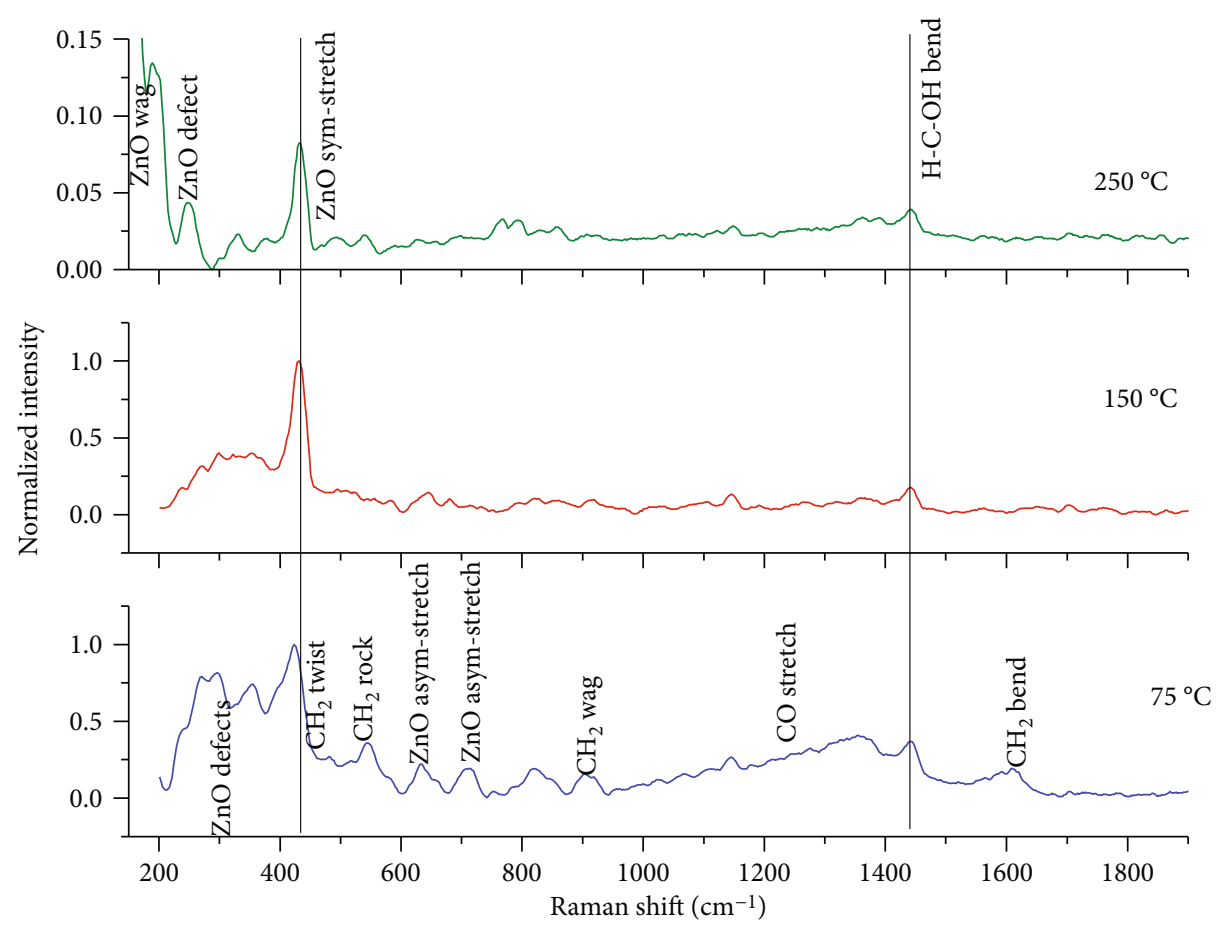

FIgURE 7: Raman spectra of the poly(vinyl alcohol)- (PVA-) filled layered double hydroxide composite fibers (samples CF75, CF150, and CF25) are plotted vertically in order of increasing annealing temperature. The positions of characteristic vibrations of ZnO and PVA are marked by vertical lines on the plot.

wagging, bending, and stretching modes of $\mathrm{CH}_{2}$ along with $\mathrm{CO}$ bending and stretching modes. In the absence of centrosymmetry, the selection rules permit observance of all vibrations in the Raman spectra. However, due to atomic displacement and rearrangement, the bulk vibration frequencies are expected to show some frequency shifts in comparison with related molecular modes.

Taking into account the fact that the crystal structure of $\mathrm{ZnO}-\mathrm{LDH}$ changes on annealing, the Raman studies were performed to optically explore the structural changes of PVA-filled $\mathrm{ZnO}-\mathrm{LDH}$ hybrid composite fibers taken after annealing at $75^{\circ} \mathrm{C}, 150^{\circ} \mathrm{C}$, and $250^{\circ} \mathrm{C}$. The Raman spectra recorded for the three fiber samples CF75, CF150, and CF250 are shown in Figure 7. The characteristic vibrational peak for zinc oxide is a $\mathrm{Zn}-\mathrm{O}-\mathrm{Zn}$ symmetrical stretching mode, which is found in all samples, and its position in the graph is marked by a straight line, at $434 \mathrm{~cm}^{-1}$. Notably, the characteristic peak intensifies with the heat treatment, indicating strengthening of the oxide phase of $\mathrm{ZnO}-\mathrm{LDH}$ system, which is in agreement with our XRD results. Concurrently, the bond softening was also evident in the form of the $\sim 15-$ $\mathrm{cm}^{-1}$ shift of the characteristic peak towards higher energies. Such bond softening is indicative of either the formation of a new phase, which was in fact proved previously in our XRD studies, or the decay in the existing crystalline order. Thus, the Raman results provided supportive structural information on the $\mathrm{ZnO}$-LDO phase. Similarly, the characteristic vibration of enol, HC-OH stretching mode, was found present in all the annealed samples and is marked by a straight line at $1444 \mathrm{~cm}^{-1}$ in the Raman plot. The presence of enol modes of PVA shows the robust PVA fiber structure with respect to heating without any dehydroxylation of alcohol.

\section{Conclusions}

Greener low temperature sol-gel method was used for the synthesis of the Zn-based LDH powders at lower synthesis temperature. Hexagonal structural phase of as-grown $\mathrm{LDH}$ particulates dried at $75^{\circ} \mathrm{C}$ was observed. A structural modification of tetragonal phase transformation was found in the furnace dried particulates at $\approx 250^{\circ} \mathrm{C}$. The morphological changes of $\mathrm{LDH}$ powders upon heating were also studied by electron microscopy. Interestingly, the platelet- (layered) type as-grown LDH particulates change their shape into the faceted particulates, of size $\approx 45 \mathrm{~nm}$, on heating further corroborating the phase transformation. In addition, the XPS spectra of modified LDH showed a steep rise in the native$\mathrm{O}$ coordination (up to $74 \%$ ) in $\mathrm{LDH}$ conforming the phase transformation.

The PVA/Zn-LDH-filled nanocomposite fibers were prepared by electrospinning process. The composite fiber samples showed straight and elongated morphology of fibers of intertwined nature along with fiber diameter uniformity. Thermal characteristics of the fibers were studied at up to $250^{\circ} \mathrm{C}$ heating. Nonuniform in the TGA losses of fibers was explained using a novel interaction mechanism between modified LDH and PVA fibers. Properties of the fibers were also examined by Raman spectroscopy and electron microscopy. Theoretical calculations of the characteristic vibrations of zinc oxide and the enol monomer constituents of the PVA 
fiber were performed. The characteristic vibrations of $\mathrm{ZnO}$ and PVA in the fiber showed no change in position and shape with heat treatment indicating the weak dehydroxylation of PVA. However, dehydration effects on fibers were clearly observed along with the disappearance of various $\mathrm{CH}_{2}$ vibrations on annealing. Although our studies showed greener synthesis of $\mathrm{Zn}$-based $\mathrm{LDH}$ layers, we have found the efficient thermal decomposition of PVA due to LDO fillers at low temperature. Further studies are nevertheless required to explore the processes involved in the PVA and $\mathrm{LDH}$ dispersion and degradation during annealing.

\section{Data Availability}

All data used in this study are available and public (no restrictions).

\section{Conflicts of Interest}

The authors declare that there is no conflict of interest regarding the publication of this paper.

\section{Acknowledgments}

The authors acknowledge the Deanship of Scientific Research at King Faisal University for the financial support under the annual research project (Grant No. 170054).

\section{References}

[1] X. Yang, V. Salles, Y. V. Kaneti et al., "Fabrication of highly sensitive gas sensor based on $\mathrm{Au}$ functionalized $\mathrm{WO}_{3}$ composite nanofibers by electrospinning," Sensors and Actuators $B$ : Chemical, vol. 220, pp. 1112-1119, 2015.

[2] P. Nalawade, B. Aware, V. Kadam, and R. Hirlekar, "Layered double hydroxides: a review," Journal of Scientific \& Industrial Research, vol. 68, pp. 267-272, 2009.

[3] M. J. Wu, J. Z. Wu, J. Zhang et al., "A review on fabricating heterostructures from layered double hydroxides for enhanced photocatalytic activities," Catalysis Science \& Technology, vol. 8, no. 5, pp. 1207-1228, 2018.

[4] L. Zhang, L. Li, X. Sun, P. Liu, D. Yang, and X. Zhao, "ZnOlayered double hydroxide@graphitic carbon nitride composite for consecutive adsorption and photodegradation of dyes under UV and visible lights," Materials, vol. 9, no. 11, p. 927, 2016.

[5] M. V. Bukhtiyarova, "A review on effect of synthesis conditions on the formation of layered double hydroxides," Journal of Solid State Chemistry, vol. 269, pp. 494-506, 2019.

[6] V. Rives and M. Angeles Ulibarri, "Layered double hydroxides (LDH) intercalated with metal coordination compounds and oxometalates," Coordination Chemistry Reviews, vol. 181, no. 1, pp. 61-120, 1999.

[7] G. Mishra, B. Dash, and S. Pandey, "Layered double hydroxides: a brief review from fundamentals to application as evolving biomaterials," Applied Clay Science, vol. 153, pp. 172-186, 2018.

[8] M. I. Baker, S. P. Walsh, Z. Schwartz, and B. D. Boyan, “A review of polyvinyl alcohol and its uses in cartilage and orthopedic applications," Journal of Biomedical Materials Research
Part B: Applied Biomaterials, vol. 100B, no. 5, pp. 1451-1457, 2012.

[9] S. Moulay, "Review: Poly(vinyl alcohol) functionalizations and applications," Polymer-Plastics Technology and Engineering, vol. 54, no. 12, pp. 1289-1319, 2015.

[10] B. Ramaraj and S. N. Jaisankar, "Thermal and morphological properties of poly (vinyl alcohol) and layered double hydroxide (LDH) nanocomposites," Polymer-Plastics Technology and Engineering, vol. 47, no. 7, pp. 733-738, 2008.

[11] M. Kotal and A. K. Bhowmick, "Polymer nanocomposites from modified clays: recent advances and challenges," Progress in Polymer Science, vol. 51, pp. 127-187, 2015.

[12] S. Lin, X. Liu, J. Liu et al., "Anti-fatigue-fracture hydrogels," Science Advances, vol. 5, no. 1, article eaau8528, 2019.

[13] A. E. Danks, S. R. Hall, and Z. Schnepp, "The evolution of 'solgel' chemistry as a technique for materials synthesis," Materials Horizons, vol. 3, no. 2, pp. 91-112, 2016.

[14] N. D. Johari, Z. M. Rosli, J. M. Juoi, and S. A. Yazid, "Comparison on the Tio 2 crystalline phases deposited via dip and spin coating using green sol-gel route," Journal of Materials Research and Technology, vol. 8, no. 2, pp. 2350-2358, 2019.

[15] M. Hu, X. Yan, X. Hu, R. Feng, and M. Zhou, "High-capacity adsorption of benzotriazole from aqueous solution by calcined Zn-Al layered double hydroxides," Colloids and Surfaces A: Physicochemical and Engineering Aspects, vol. 540, pp. 207214, 2018.

[16] Á. Deák, L. Janovák, E. Csapó et al., "Layered double oxide (LDO) particle containing photoreactive hybrid layers with tunable superhydrophobic and photocatalytic properties," Applied Surface Science, vol. 389, pp. 294-302, 2016.

[17] S. Sohrabnezhad and S. Taghaddosnezhad, "Incorporation of $\mathrm{ZnO}-\mathrm{Al}$ layered double oxide in AgMCM-41 nanocomposite for photodegradation of dye," Applied Clay Science, vol. 157, pp. 130-138, 2018.

[18] J. Huang, Z. Yang, R. Wang, Z. Zhang, Z. Feng, and X. Xie, "Zn-Al layered double oxides as high-performance anode materials for zinc-based secondary battery," Journal of Materials Chemistry A, vol. 3, no. 14, pp. 7429-7436, 2015.

[19] L. Zhang, W. Rong, Y. Chen, C. Lu, and L. Zhao, "A novel acetone sensor utilizing cataluminescence on layered double oxide," Sensors and Actuators B: Chemical, vol. 205, pp. 8287, 2014.

[20] M. Bognitzki, T. Frese, M. Steinhart et al., "Preparation of fibers with nanoscaled morphologies: electrospinning of polymer blends," Polymer Engineering \& Science, vol. 41, no. 6, pp. 982-989, 2001.

[21] J. Han, L. Xiong, X. Jiang, X. Yuan, Y. Zhao, and D. Yang, "Biofunctional electrospun nanomaterials: from topology design to biological applications," Progress in Polymer Science, vol. 91, pp. 1-28, 2019.

[22] P. Tranchard, S. Duquesne, F. Samyn, B. Estebe, and S. Bourbigot, "Kinetic analysis of the thermal decomposition of a carbon fibre-reinforced epoxy resin laminate," Journal of Analytical and Applied Pyrolysis, vol. 126, pp. 14-21, 2017.

[23] Y. Xu, W. J. Brittain, R. A. Vaia, and G. Price, "Improving the physical properties of PEA/PMMA blends by the uniform dispersion of clay platelets," Polymer, vol. 47, no. 13, pp. 45644570, 2006.

[24] F. Neese, “The ORCA program system," Wiley Interdisciplinary Reviews: Computational Molecular Science, vol. 2, no. 1, pp. 73-78, 2012. 
[25] J. Rodríguez-Carvajal, "Recent advances in magnetic structure determination by neutron powder diffraction," Physica B, vol. 192, no. 1-2, pp. 55-69, 1993.

[26] X. Long, Z. Wang, S. Xiao, Y. An, and S. Yang, “Transition metal based layered double hydroxides tailored for energy conversion and storage," Materials Today, vol. 19, no. 4, pp. 213226, 2016.

[27] C. D. Wagner, L. E. Davis, M. V. Zeller, J. A. Taylor, R. H. Raymond, and L. H. Gale, "Empirical atomic sensitivity factors for quantitative analysis by electron spectroscopy for chemical analysis," Surface and Interface Analysis, vol. 3, no. 5, pp. 211-225, 1981.

[28] T. Subbiah, G. S. Bhat, R. W. Tock, S. Parameswaran, and S. S. Ramkumar, "Electrospinning of nanofibers," Journal of Applied Polymer Science, vol. 96, no. 2, pp. 557-569, 2005. 